|| Print ISSN: 2589-7837 || Online ISSN: 2581-3935 ||

International Journal of Medical Science and Diagnosis Research (IJMSDR)

Available Online at www.ijmsdr.com

NLM (National Library of Medicine ID: 101738824)

\title{
Correlation between Ultrasonography and Fine Needle Aspiration Cytology (FNAC) Findings in Patients with Thyroid Lesions
}

\author{
Md. Kalim Akhtar ${ }^{1 *}$, Dambar Sah ${ }^{1}$, Rajesh Acharya ${ }^{1}$, Akhilesh Kumar Jha ${ }^{1}$, \\ Rajan Kumar Mahato ${ }^{1}$, Bikranta Rimal ${ }^{1}$, Shashi Sekhar Prasad Shah ${ }^{1}$, Fahad \\ Alam ${ }^{2}$, Alok Kumar Singh ${ }^{3}$, Asraf Hussain ${ }^{3}$ \\ ${ }^{1}$ Department of Radiodiagnosis, National Medical College, Birgunj, Nepal \\ ${ }^{2}$ Lecturer, Department of Pathology, National Medical College, Birgunj, Nepal \\ ${ }^{3}$ Lecturer, Department of Internal Medicine, National Medical College, Birgunj, Nepal
}

\section{Conflicts of Interest: Nil}

Corresponding author: Dr Md. Kalim Akhtar

DOI: https://doi.org/10.32553/ijmsdr.v5i8.837

\begin{abstract}
:
Background: Thyroid nodules are common presentation in patients having thyroid disorders. There is approximately $4-5 \%$ incidence of clinically apparent thyroid lesions in general populations. Thyroid nodules are about four times more common in females than in males. The present study aims to diagnose the thyroid lesions and evaluate the correlation between ultrasonography (USG) and Fine Needle Aspiration Cytology (FNAC) reports. To determine the sensitivity of ultrasonography in detecting thyroid lesions.
\end{abstract}

Method: This was hospital based prospective study carried in 94 patients who came to radiology department for USG neck, after clinical examination from medicine, surgery and ENT departments. Those patients with thyroid lesions were followed and advised for USG guided FNAC of thyroid swelling. The patients who were advised for FNAC, and gave consent for procedure were included in the study. The USG guided FNAC was done and was further evaluated by pathologist.

Results: Out of 94 cases, 85 were benign nodules and 9 were malignant nodules by USG which were further confirmed by FNAC with results of 87 benign and 7 malignant. The USG diagnosed the benign thyroid nodule with sensitivity of $96.55 \%$ and specificity of $85.71 \%$, positive predictive value $98.82 \%$, negative predictive value $66.67 \%$, accuracy $95.74 \%$. The result revealed that there is a strong relation between diagnoses of benign thyroid lesions by USG and final diagnosis by FNAC $(\mathrm{P}=0.001)$.

Conclusion: High resolution grey scale imaging features can differentiate benign and malignant lesions. USG is very helpful for FNAC, characterization of nodules and provides differential diagnosis in those patients affecting with thyroid disorders.

Keywords: FNAC, benign thyroid nodules, malignant thyroid lesions, USG

\section{Introduction:}

Thyroid nodules are common findings on grey scale imaging. They are formed within thyroid parenchyma and can be solid, cystic or mixed type. ${ }^{1}$ Ultrasound is the first line of investigation in evaluation of thyroid gland and has high sensitivity even in the detection of tiny nodules. ${ }^{2}$ About $4-5 \%$ of normal population have incidence of thyroid lesion of which female are more commonly affected than males. Most common thyroid nodules are benign comprising of $90 \%$ followed by malignant $10 \%{ }^{3}{ }^{4}$ USG of the thyroid gland is considered as one of the most sensitive method for diagnosis of thyroid lesions. The features of malignancy in Ultrasound include marked 
hypoechogenecity,

presence

of microcalcifications, irregular margins, and nodules with shape taller than wide and intra-nodular hypervascularity in color Doppler. ${ }^{5,6}$

The goal of this study is to differentiate between benign and malignant thyroid nodule using ultrasonography and correlate with fine needle aspiration cytology (FNAC) findings.

\section{Methods}

This is a prospective hospital-based study that was carried out 94 cases in department of radiology of National Medical College, Birgunj. Among patients referred for USG neck from the ENT, Surgery, and Medicine departments after clinical examination of thyroid swelling irrespective with their age group, gender and clinical complaints that were advised for FNAC and gave consent were included in the study. Those patients who went for surgery and/or radiotherapy, and those who refused for giving consent were excluded from the study.

Scans were conducted using $7 \mathrm{MHz}$ linear probe with grey scale imaging followed by color Doppler study in Samsung sonoace R7, Medison and TOSHIBA machines.

USG neck was done by standard procedure, patients were put in supine position with neck hyper extended using the pillow under the shoulder. The neck was then scanned in sagittal, transverse, and oblique section so that thyroid gland and neck vessels would be easily examined.
Both the lobe of thyroid gland and isthmus were examined.

The nodules were characterized further using USG features like echogenicity, shape, margin, internal component, height and width, calcifications and vascularity. The detected thyroid nodules were advised for USG guided FNAC evaluation.

FNAC was performed using 10ml disposable syringe with a proper safety measures. Slide was prepared and cytological examination was performed by pathologist.

The data were collected and were expressed in frequency and percentage. For relationship between variables, chi-square test was used and sensitivity and specificity were calculated.

The study was conducted from October 2020 to July 2021.

\section{Results}

Out of 94 patient studied there were 10 (10.64\%) males and $84(89.36 \%)$ females with male to female ratio of $1: 8.4$. The mean age (SD) of male and female was 38.30 (11.742) years and 38.14 (13.064) years respectively and overall mean age (SD) of patients was 38.16 (13.198) years. So according to this study thyroid lesion are more common in female than male. In this study 30 $(31.92 \%)$ patients were belongs to $30-39$ year age group and there was around $90 \%$ female belong to between 20 to 50 age group. the youngest patient was 16 years of age and eldest was 72 . The age wise gender distribution is shown in table 1 .

Table 1: Age wise Gender distribution of thyroid lesions.

\begin{tabular}{|c|c|c|c|}
\hline \multirow{2}{*}{ Age group } & \multicolumn{2}{|l|}{ Gender } & \multirow{2}{*}{$\begin{array}{l}\text { Total Patients }(n=94) \\
(\%)\end{array}$} \\
\hline & Male $(\mathrm{N}=10)(\%)$ & Female $(\mathrm{N}=84)(\%)$ & \\
\hline $10-19$ & $1(16.67)$ & $5(83.33)$ & $6(6.38)$ \\
\hline $20-29$ & $2(9.09)$ & $20(90.91)$ & $22(23.41)$ \\
\hline $30-39$ & $3(10)$ & $27(90)$ & $30(31.92)$ \\
\hline $40-49$ & $2(10.53)$ & $17(89.47)$ & $19(20.21)$ \\
\hline $50-59$ & $1(10)$ & $9(90)$ & $10(10.64)$ \\
\hline $60-69$ & $1(16.67)$ & $5(83.33)$ & $6(6.38)$ \\
\hline \multirow[t]{2}{*}{$70-79$} & $0(0)$ & $1(100)$ & $1(1.06)$ \\
\hline & \multicolumn{2}{|c|}{ Mean \pm Standard deviation } & \\
\hline Age & $38.3 \pm 11.742$ & $38.14 \pm 13.064$ & $38.16 \pm 13.198$ \\
\hline
\end{tabular}




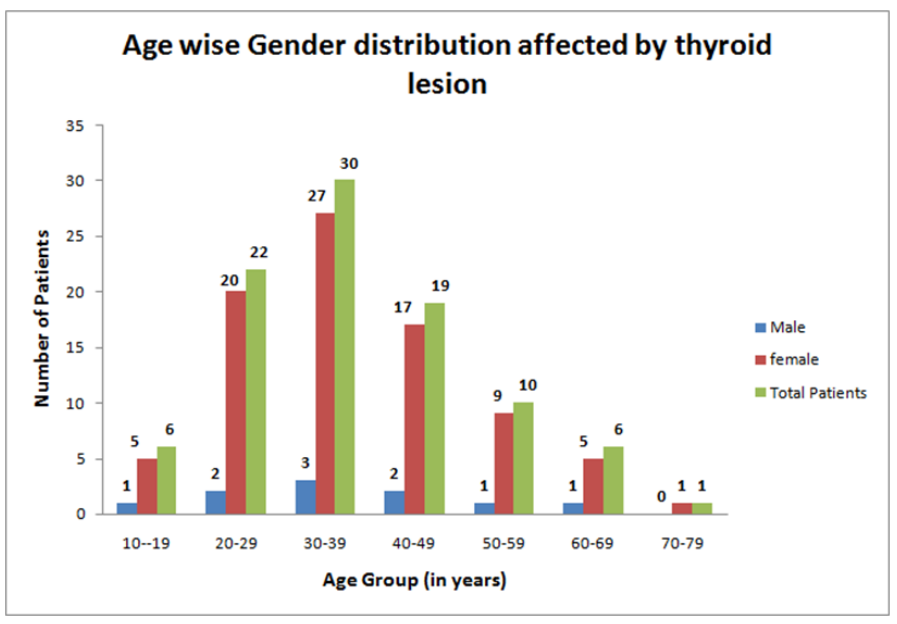

\section{Chart 1: Bar graph showing Age wise Gender distribution of the thyroid lesions}

Bar graph is representing incidence of cases with respect to age and gender. Most common population and age group that were affected by thyroid nodule were female and in between 30-39 years of age respectively.

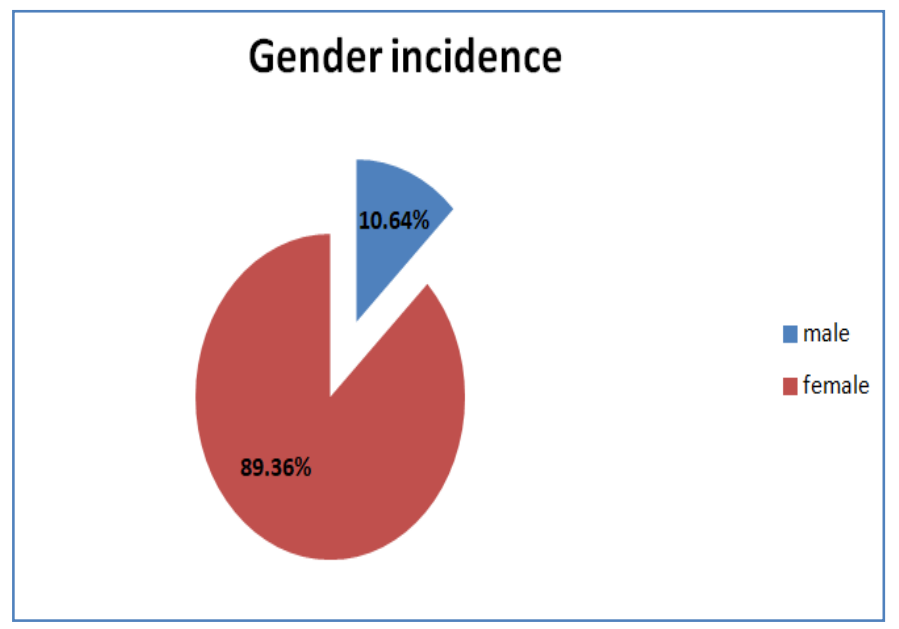

\section{Chart: 2: Gender distribution of population}

In this study, $89.36 \%$ were female and $10.64 \%$ were male. The male to female ratio was $1: 8.6$

Table 2: Radiological diagnosis and FNAC diagnosis of thyroid lesion related statistics.

\begin{tabular}{|l|l|l|l|}
\hline & Diagnosis & Number of patients $(\mathrm{n}=94)$ & Percentage \\
\hline Radiological & Nodular goiter & 21 & 22.34 \\
\cline { 2 - 4 } & Colloid goiter & 34 & 36.17 \\
\cline { 2 - 4 } & Hashimoto & 18 & 19.14 \\
\cline { 2 - 4 } & Grave disease & 12 & 12.76 \\
\cline { 2 - 4 } & Papillary ca & 3 & 3.19 \\
\cline { 2 - 4 } & Follicular ca & 3 & 3.19 \\
\cline { 2 - 4 } & Medullary ca & 2 & 2.12 \\
\cline { 2 - 4 } & Ana-plastic ca & 1 & 1.06 \\
\hline
\end{tabular}




\begin{tabular}{|l|l|l|l|}
\hline FNAC & Nodular goiter & 19 & 20.2 \\
\cline { 2 - 4 } & Colloid goiter & 33 & 35.1 \\
\cline { 2 - 4 } & Hashimoto & 24 & 25.5 \\
\cline { 2 - 4 } & Grave disease & 11 & 11.7 \\
\cline { 2 - 4 } & Papillary ca & 4 & 4.3 \\
\cline { 2 - 4 } & Follicular ca & 2 & 2.1 \\
\cline { 2 - 4 } & Medullary ca & 1 & 1.1 \\
\cline { 2 - 4 } & Ana-plastic ca & 0 & 0.0 \\
\hline
\end{tabular}

Table 2 shows the radiological and cytological diagnosis of thyroid lesion related statistics of total patients. Most common radiological findings was colloid goiter 34 (36.17\%), followed by Hashimoto thyroiditis $18(19.14 \%)$ and nodular goiter $21(22.34 \%)$ and the most common finding of cytological diagnosis of thyroid nodules in which colloid goiter was 33 (35.17\%) followed by nodular goiter 19 $(20.2 \%)$ and hashimotos 24 (25.5\%).

Table 3: Relationship between Radiological and FNAC diagnosis of benign and malignant thyroid nodules.

\begin{tabular}{|l|l|l|l|l|}
\hline \multirow{2}{*}{$\begin{array}{l}\text { Radiological } \\
\text { diagnosis(n=94) }\end{array}$} & \multicolumn{2}{|l|}{ Pathological diagnosis(n=94) } & \multirow{2}{*}{ No of cases } & \multirow{2}{*}{ P-value* } \\
\cline { 2 - 4 } Benign & Benign & Malignant & 85 & \\
\hline Malignant & 34 & 1 & 6 & 9 \\
\hline Total & 87 & 7 & 94 & \\
\hline Diagnostic Test & \multicolumn{5}{|l|}{} \\
\hline Sensitivity & Specificity & $\begin{array}{l}\text { Positive Predictive } \\
\text { Value }\end{array}$ & negative predictive value & accuracy \\
\hline $96.55 \%$ & $85.71 \%$ & $98.82 \%$ & $66.67 \%$ & $95.74 \%$ \\
\hline
\end{tabular}

*Yates's chi square test $\chi^{2}=41.58$ is applied

Above mentioned table 3 suggest that out of 94 cases USG findings of 85 cases were suggestive of benign features whereas that of only 9 patients were suggestive of malignant features. These ultrasonography features were further compared by FNAC findings. FNAC results suggest 87 cases were benign and 7 cases where malignant. In this study the most of the cases were benign and the
USG diagnosis had a highly significant relation (Pvalue $=0.001$ ) to FNAC diagnosis result.

So we finally correlate the benign cases sensitivity and specificity of USG. Considering cytological data as a standard, it was revealed that USG has sensitivity of $96.55 \%$, followed by specificity of $85.71 \%$, positive predictive value $98.82 \%$, negative predictive value $66.67 \%$ and accuracy $95.74 \%$.

Table 4: Factors of USG features associated withRadiological features of various benign and malignant thyroid lesions.

\begin{tabular}{|l|l|l|l|}
\hline USG features & Benign (\%) & Malignant (\%) & P-value* \\
\hline Echogenicity & $54(100)$ & $0(0)$ & \multirow{2}{*}{0.006} \\
\hline Hyper echoic & $28(80)$ & $7(20)$ & \\
\hline Hypo echoic & $3(60)$ & $2(40)$ & \\
\hline Heterogeneous &
\end{tabular}




\begin{tabular}{|c|c|c|c|}
\hline Kalim Akhtar et al & \multicolumn{3}{|c|}{ International Journal of Medical Science and Diagnosis Research (IJMSDR) } \\
\hline \multicolumn{4}{|l|}{ Internal content } \\
\hline Solid & $44(86.27)$ & $7(13.73)$ & \multirow{3}{*}{0.320} \\
\hline Cystic & $25(100)$ & $0(0)$ & \\
\hline Mixed & $16(88.89)$ & $2(11.11)$ & \\
\hline \multicolumn{4}{|l|}{ Shape } \\
\hline wider than Taller & $77(91.67)$ & $7(8.33)$ & \multirow{2}{*}{0.538} \\
\hline taller than wider & $8(80)$ & $2(20)$ & \\
\hline \multicolumn{4}{|l|}{ Margin } \\
\hline Well defined & $68(98.55)$ & $1(1.45)$ & \multirow{2}{*}{0.001} \\
\hline Ill defined & $17(68)$ & $8(32)$ & \\
\hline \multicolumn{4}{|l|}{ Calcification } \\
\hline Present & $13(61.90)$ & $8(38.10)$ & \multirow{2}{*}{0.001} \\
\hline Absent & $72(98.63)$ & $1(1.37)$ & \\
\hline \multicolumn{4}{|l|}{ Comet tail artifact } \\
\hline Present & $11(100)$ & $0(0)$ & \multirow{2}{*}{0.546} \\
\hline Absent & $74(89.16)$ & $9(10.84)$ & \\
\hline \multicolumn{4}{|l|}{ Peripheral halo } \\
\hline Present & $24(88.89)$ & $3(11.11)$ & \multirow{2}{*}{0.748} \\
\hline Absent & $61(91.04)$ & $6(8.96)$ & \\
\hline \multicolumn{4}{|c|}{ Internal vascularity } \\
\hline Present & $30(78.95)$ & $8(21.05)$ & \multirow{2}{*}{0.006} \\
\hline Absent & $55(98.21)$ & $1(1.79)$ & \\
\hline
\end{tabular}

\section{*Yates's chi square test is applied}

Table 4 shows the USG factors associated with Radiological features of various benign and malignant thyroid lesions. Most of the nodule has benign features in our study, with hyper echogenicity in $54(100 \%)$ cases, internal content solid in $44(86.24 \%)$ cases, wider than taller shape in $77(91.67 \%)$ cases, well defined margin in 68 $(98.55 \%)$ cases. There was significant relation found between USG features echogenicity $(\mathrm{P}=0.006)$ and margin $(\mathrm{P}=0.001)$ and Radiological features of benign and malignant thyroid lesions and also had significant relation between calcification $(\mathrm{P}$ value $=0.001)$ and internal vascularity $(\mathrm{P}=0.006)$ with radiological features which had $72(98.63 \%)$ cases absent calcification and $55(98.21 \%)$ cases absent internal vascularity in benign. Other features were not showing significant relation with radiological features because they might have absent features in benign.

\section{Discussion}

Total numbers of 94 patients with various thyroid swelling were evaluated with grey scale imaging and FNAC. FNAC cytology is gold standard for evaluation of thyroid nodule. This study identified the strong correlation between USG and FNAC diagnosis of thyroid nodules. In current study the thyroid lesion were found to be more common in females than in the males.

Avinash et. al 2016 study also revealed more commonly affected gender were female $81.5 \%$ of the occurrence. The most common age group affected by thyroid nodules was between 31-40 years, followed by 41-50 years with percentage of $41 \%$ and $25 \%$ respectively. ${ }^{7}$ In this study also most common age group affected was 30-39years (32.97\%). Gyawali M and Sharma study in Nepal also revealed that the mean age group affected by thyroid nodule was 38 years which was similar to this study. ${ }^{8}$ The male to female ratio was 1: 8.4.

In this study, USG revealed that $90.42 \%$ patient has benign nodule and $9.57 \%$ have malignant nodule in ultrasonography however in FNAC diagnosed $92.55 \%$ benign and $7.44 \%$ were malignant nodules. Similar results were published 
by many authors in their studies about benign and malignant thyroid nodules that were correlated with USG and fine-needle aspiration cytology in which it was revealed that $8.57 \%$ were malignant nodules. ${ }^{9,} 10$ Patel NR et.al also revealed in their study $6 \%$ was malignant and $94 \%$ were benign thyroid lesion on USG. ${ }^{11}$

In the study of Krishna et al. out of 80 cases, 45 cases $(56.25 \%)$ were colloid goiter, the most common benign lesion. ${ }^{12}$ Similarly, Patel NR et al also found the most common lesion was colloid goiter with $36 \%$ of people were affected. ${ }^{10}$ In this study also the most common nodules were colloid goiter $35.1 \%$, followed by Hashimoto thyroiditis $25.5 \%$ and nodular goiter $20.2 \%$ by FNAC. USG shows colloid goiter $36.17 \%$ was the most common followed by nodular goiter $22.34 \%$ and hasimato $19.14 \%$.

Arun C. Nachhiappan et al. described the benign thyroid nodules which appear with uniform halo, predominantly cystic, in USG whereas malignant lesion has features like micro calcification, extension beyond thyroid margin and marked hypoechogenicity. ${ }^{13}$ In this study various ultrasonography features like echogenicity, solid, cystic, mixed nodule, taller than wider and viceversa, margin, halo, calcification, comet tail, and vascularity were observed in which the most of the lesion has benign features, with hyperechogenicity in 54 cases, wider than taller in 77 cases and well defined margin in 68 cases and USG features echogenicity, margin, calcification and internal vascularity has showed the significant result with radiological features. Those were further confirmed by cytological analysis.

Alam T et al. ${ }^{14}$ also reported that USG has $82 \%$ overall diagnostic accuracy for malignant lesion. Popli MB et al. revealed that US shows 87.2\% accuracy in diagnosis for thyroid nodules. ${ }^{15}$

The result of this study revealed that USG has sensitivity of $96.55 \%$, followed by specificity of $85.71 \%$, positive predictive value of $98.82 \%$, and negative predictive value of $66.67 \%$ and accuracy of $95.74 \%$. These results were consistent with a study done in Republic of Yemen which reported that ultrasonography can predict benign thyroid lesions with high sensitivity of $96.8 \%$, specificity $71.42 \%$, positive predictive value $98.38 \%$ and negative predictive value of $55.55 \%{ }^{1}$

\section{Conclusion}

High resolution grey scale imaging features can differentiate benign and malignant lesions. USG is very helpful for FNAC, characterization of nodules and provide differential diagnosis in those patients affecting from thyroid disorders.

\section{Limitations:}

The limitation of this study was that most of the diagnosis was based on cytological examination rather than histological evidence. Recent imaging modalities like Elastography and Spectral study were not used. In case of multiple thyroid nodules only the single specific nodule was evaluated by the FNAC.

Funding: No funding sources

Ethical approval: the study was approved by the Institutional ethics committee

\section{References}

1. Alshabbi SA, BinnuaidAA. Diagnostic accuracy of ultrasonography versus fineneedle-aspiration cytology for predicting benign thyroid lesions. Pak J Med sci.2019;35(3):630-635

2. Dhanadia A, Shah H, Dave A. Ultrasonographic and FNAC correlation of thyroid lesions. gujrat medical journal.2014;69(1):75-81

3. Altavillia G, Pasacale M, Nenici. FNAC of thyroid gland disease.Acta cytological. 1990;34:251-6

4. Bouvet M, fiedldmann JI. Surgical management of thyroid nodule: patient selection based on the result of the FNAC, Laryngoscope. 1992;102:1353-6

5. Cooper DS, Doherty GM, Haugen BR. Revised American Thyroid Association management guidelines for patients with thyroid nodules and differentiated thyroid cancer. Thyroid. 2009; 19(11):1167-1214.

6. Solbiati L, charboneau JW, Osti V. The thyroid gland. In: Rumack CM, et al. 
editors. Diagnostic Ultrasound. 3rd ed. St Louis, Missouri, USA; 2010. p. 735-770.

7. Avinash B, Ahmed N, Sreedevi T, Swapna Ch, Latha RM, Babu J. USG to differentiate benign from malignant thyroid nodules. International journal of scientific study. Aug 2016;4:5:81-87

8. Gyawali M, Sharma P. Study of role of ultrasonography in evaluation of thyroid nodules. Nepalese journal of radiology 2019;9(13):2-6

9. Elaraj DM. Evaluation of the thyroid nodule. USA: Springer science \& business media; 2009. p. 23-35.

10. Menegassi J, Bordin V, Oliveira SS. Diagnostic accuracy between fine needle aspiration biopsy (FNA) and pathological examination of the thyroid. Brazilian journal of Pathology and Laboratory Medicine. 2013;49(4):288-293

11. Patel NR, Patel AV, Patel VV, Vadher PR, Manali BK. Ultrasonographic and fine needle aspiration cytology correlation of thyroid gland:a study of 100 cases.Int J otorhinolryngol head neck surg.2019 Mar;5(2):319-325

12. Borah KK, Medhi G, Sarma A. thyroid swelling evaluation by ultrasonography with FNAC correlations. J Med Sci Clin Res, 2016;4:10089-99

13. Arun C. Nachiappan, Zeyad A. Metwalli, Brian S. Hailey, Rishi A. Patel, Mary L. Ostrowski, and David M. WynneThe Thyroid: Review of Imaging Features and Biopsy Techniques with RadiologicPathologic Correlation; RadioGraphics :2014 34:2, 276-293

14. Alam T, Khattak YJ, Beg M. Diagnostic accuracy of ultrasonography in differentiating benign and malignant thyroid nodules using fine needle aspiration cytology as the reference standard. Asian Pac J cancer Prev. 2014;15(22):1003910043

15. Popli MB, Rastogi A, Bhalla P, Solanki Y. Utility of gray scale ultrasound to differentiate benign from malignant thyroid nodules. Indian J Radiol Imaging .2012;22: 63-68 